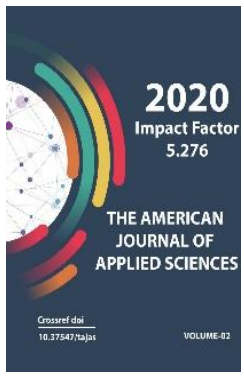

Copyright: Original content from this work may be used under the terms of the creative commons attributes 4.0 licence.

\section{Substantiation Of The Operating Mode Of The Pendulum Feeder}

\author{
Astanakulov Komil Dulliyevich \\ Doctor Of Technical Sciences, Associate Professor Tashkent Institute Of Irrigation And \\ Agricultural Mechanization Engineers, Uzbekistan
}

Kurbanov Fazliddin Kulmamatovich

Assistant, Tashkent State Agrarian University, Uzbekistan

Isakova Farida Jazilbaevna

Assistant, Tashkent State Agrarian University, Uzbekistan

\title{
ABSTRACT
}

Today, auto-feeding is the most effective way of feeding and it is less time consuming because feeding fish is a mandatory process in all enterprises, engaged in fish farming.

\section{KEYWORDS}

Feeder, fish, fish species, protein, fish farming, development of fish, high-calorie.

\section{INTRODUCTION}

In the climatic conditions of the Republic of Uzbekistan, in the absence of large water resources and with a shortage of live food organisms, such as zooplankton, the use of high-calorie compound feeds will be very effective. Currently, for some cultivated fish species, feeds are being developed containing hydrolysis products and a large amount of low molecular weight protein.
Automated control of all processes in pond fish farming starting from pond preparation for stocking of fish to placement and production of commercial fish will significantly increase the efficiency of fish farming by $70-$ $80 \%$ thus increasing the overall profit by $20-$ $30 \%[1]$. In this regard, in the industrial cultivation of fish, the use of biologically active substances that promote the absorption of plant proteins is of great 
importance. The metabolic rate in fish is determined by the temperature of the water. The temperature spectrum of vital activity occurs both more intense and less intense. In cold waters, metabolism proceeds more slowly than in warm waters, because, in warm waters, oxidative processes are activated in its tissues, and oxygen shortage increases. With an increasing of water temperature, the content of dissolved oxygen decreases in fish and the intensity of respiration increases. The best digestion of feed occurs at a water temperature of $10-15^{\circ} \mathrm{C}$, and the maximum growth rate with the least use of food energy is observed at a temperature of $16-18^{\circ} \mathrm{C}$. At present, the most economical way of feeding is dry food because wet food have some disadvantages during transportation, storage, as these products contain up to $80 \%$ moisture and cannot be stored for a long time, as they quickly deteriorate [2].

\section{THE MAIN FINDINGS AND RESULTS}

Physiologically adequate to this food are protein raw material hydrolysates with a certain degree of hydrolysis, characterized by a low content of free amino acids and an increased level of easily assimilated oligopolypeptides. Therefore, research is currently needed to search for food components containing a significant amount of low molecular weight protein. The nutritional needs of fish change with age, depending on the formation of digestive functions and the stage of development of fish. One of the sources of easily digestible fodder protein is industrial protein hydrolysates, autolysates, and fermentolysates, since the products of protein hydrolysis are well absorbed by early young fish. The objective is to have a good effect on the growth rate and allow a decrease in juvenile mortality, increasing in rearing efficiency and lower food costs. Insufficient amount of food at the developmental stage increases death, leads to growth retardation, and also prevents the development of the digestive system. For normal growth and development, fish need a certain amount and ratio of basic nutrients. Protein with a set of essential amino acids, fat, carbohydrates, minerals, vitamins and other biological active substances should be in the feed composition in accordance with the needs of fish. Moreover, the need for fish varies depending on age, size, water temperature and other environmental factors. It is believed that food containing at least $15 \mathrm{~g}$ of fishmeal are fully provided with minerals, fish also need vitamins and other biologically active substances. To date, the need for fish in 15 vitamins and vitamin-like substances has been established. Thus, in industrial production, the basis for the nutrition of cultivated fish is compound food, composed on the basis of dry flour-like components according to special recipes[3]. Its effectiveness depends on the level of protein, fat, carbohydrates, minerals and vitamins, as well as the balance of amino acids, fatty acids and vitamins. The main nutrients of the food are protein with essential amino acids, fat with essential fatty acids, simple and complex carbohydrates, minerals and vitamin-enzyme complexes. The latter, like vitamins, do not carry energy, but the growth and development of the body is impossible without them.

If the diet for fish has the required amount of fat and carbohydrates, then protein is used in protein metabolism for the growth of the body. With a lack of fats and carbohydrates in the food, proteins can be used as an energy source in functional metabolism. This is not economical because protein is the most expensive part of the food.

One of the most important aspects of feeding juvenile fish is to establish the correct daily feeding rate, which would satisfy the need for growing juveniles for food.

The correct food has a high physiological calorie content of 17-18 thousand $\mathrm{kJ} / \mathrm{kg}$, its 
usage requires strict rationing, taking into account the whole complex of factors affecting the establishment of daily diets. For each component of the production of fish food, there is a standard that provides for the composition and level of nutrients. Each component has its own technical storage conditions, both in mode and in duration. Optimum storage temperature, air humidity, storage layer thickness, required type of storage are also provided[4].

The analysis show that the optimal feeding scheme is granular fooding, depending on the body weight of the fish, which contributes to increased survival. Compound food come in the form of pellets of various sizes, and their composition can be combined in different ways, taking into account the size, type and age of the fish. Fodders in the form of granules have a porous structure, a specific gravity of less than one, and water does not sink for a considerable time.

In conditions of industrial fish farming, the intensity of water exchange is of great importance for feeding fish, which should ensure not only oxygen delivery, but also removal of metabolic products.

The use of automatic feeders is very effective in growing fish. To increase the efficiency of cultivation, it is necessary to observe feeding technology, which also includes the frequency of feeding and the ratio of the size of granules and body weight of fish. The problem of feeding is one of the leading places in the technological scheme of fish cultivation. Since feed should not only meet the body's needs for energy and basic nutrients, but also consist of components available for assimilation, including protein. This can be solved by balancing the fractional composition of food components and, in particular, protein. The use of new types of high-tech compound food makes it possible to grow viable young with a deficiency or complete absence of living food organisms in the diet. However, their use is difficult due to the lack of effective technologies for feeding fishThe use of automatic feeders is very effective in growing fish and reduces feed costs. Because, the efficiency of food consumption, as well as the average daily weight gain of juveniles is slightly higher, at low feed costs, in comparison with manual feeding. The main task of commercial fish farming is to grow fish in the shortest possible time and at minimal cost. One of the main factors affecting the rapid growth of fish is the maintenance of optimal growing conditions and the usefulness of feeding[5].

Feeding fish can be done until complete eating and according to certain standards. Normalization of feeding is preferable to feeding until complete eating, since it seems possible to more reliably take into account the influence of water temperature and the mass of fish grown.

Pendulum feeders are devices that deliver feed at the request of a fish, which for this purpose deflects the pendulum or pulls the ball. Pendulum feeders are the simplest and most utilitarian in their industry. These feeders are used for fish farming in pond farms, in private reservoirs. The difference between pendulum feeders is the lack of settings for the electronics and power source. The food gets enough spill out after touching the fish to the end of the rod of the feeder. Thus, the fish quickly develops a reflex, and it eats on its own, the likelihood of the appearance of not eaten food and starvation of the fish is reduced. The mechanical operation of the feeder allows you to install devices in places where the operation of electrical devices is not possible: in remote households, without connecting to power networks, in open water bodies, in inaccessible places with rare service feeders. 


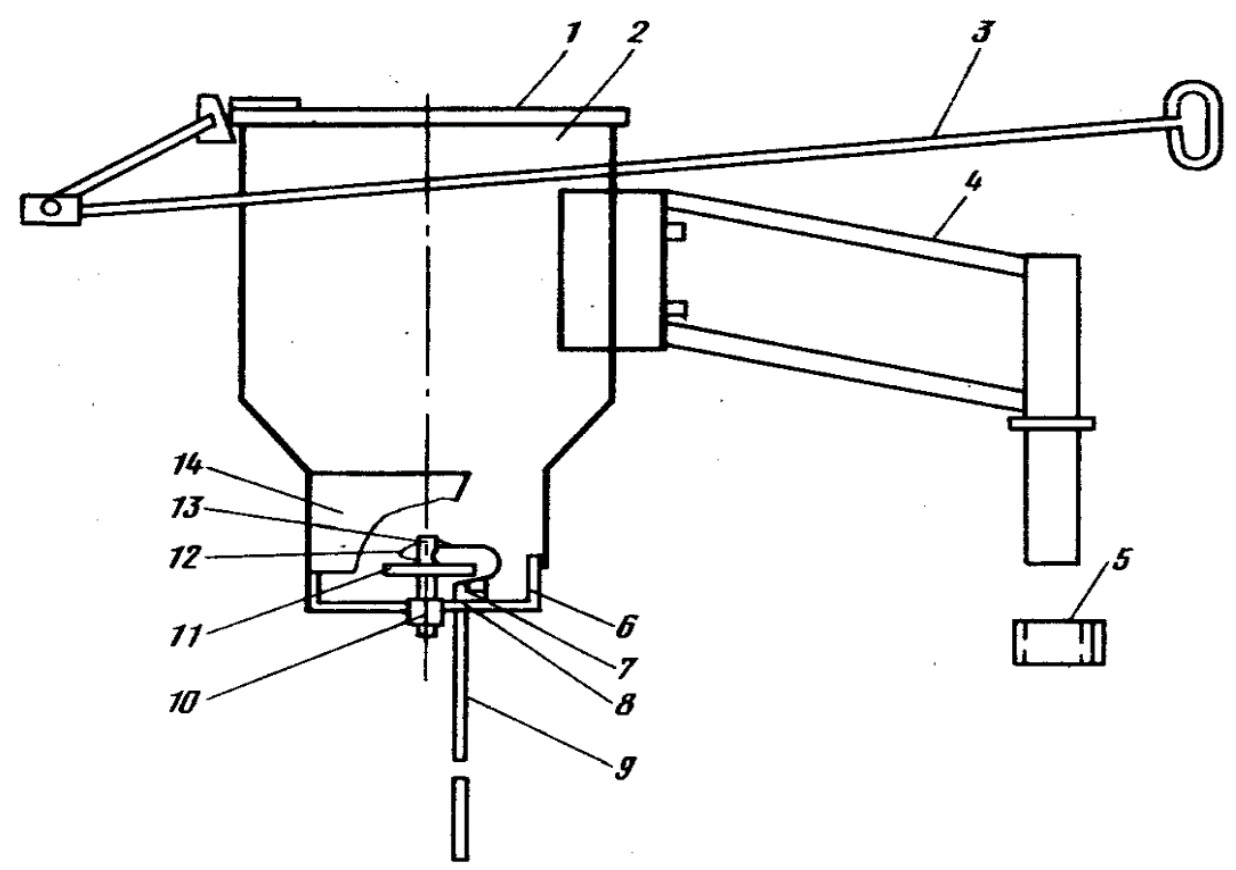

Fig. 1. Auto-feeder "Reflex T-1-50":

1-cap; 2 - hopper; 3 - traction for opening the cap; 4 - bracket. 5 - a supporting glass; 6-crossbeam; 7-screw; 8- ball support; 9-pendulum; 10 - a nut; 11 - a table; 12 - loop-shaped dropper of granul; 13 - a protective pin; 14 - moisture protective casing.

The pendulum feeder can be equipped with a hopper of any size. The main parts of the feeder are made of special plastic, which allows you to operate the device in water for a longer time than products that undergo corrosion.
Auto feeders favorably differ from devices of this type in the ability to adjust the feed. In this model, it is possible to reduce or increase the distance between the hole in the hopper and the food platform. The amplitude of the pendulum is limited by a special plastic cone.

Daily rate of feeding fish with dry granular food,\% to body weight.

\begin{tabular}{|c|c|c|c|c|c|}
\hline \multirow{2}{*}{$\begin{array}{c}\text { Temperature of } \\
\text { water, }{ }^{\mathbf{0}} \mathbf{C}\end{array}$} & \multicolumn{5}{|c|}{ Weight of fish in grams } \\
\cline { 2 - 6 } & $\mathbf{0 , 2 - 0 , 5}$ & $\mathbf{0 , 5 - 2 , 0}$ & $\mathbf{2 , 0 - 5 , 0}$ & $\mathbf{5 , 0 - 1 5 , 0}$ & more 15 \\
\hline 2 & 0,4 & 0,3 & 0,2 & 0,2 & 0,1 \\
\hline 3 & 0,7 & 0,6 & 0,5 & 0,4 & 0,2 \\
\hline 4 & 1,1 & 1,0 & 0,8 & 0,7 & 0,4 \\
\hline 5 & 1,5 & 1,4 & 1,2 & 0,9 & 0,6 \\
\hline
\end{tabular}




\begin{tabular}{|c|c|c|c|c|c|}
\hline 6 & 2,0 & 1,7 & 1,6 & 1,2 & 0,8 \\
\hline 7 & 2,4 & 2,2 & 1,8 & 1,4 & 0,9 \\
\hline 8 & 2,8 & 2,5 & 2,2 & 1,7 & 1,1 \\
\hline 9 & 3,3 & 2,9 & 2,5 & 1,9 & 0,2 \\
\hline 10 & 3,7 & 3,3 & 2,8 & 2,2 & 0,4 \\
\hline 11 & 4,1 & 3,6 & 3,1 & 2,5 & 0,5 \\
\hline 12 & 4,5 & 4,0 & 3,5 & 2,7 & 0,7 \\
\hline 13 & 4,9 & 4,4 & 3,8 & 3,0 & 0,8 \\
\hline 14 & 5,4 & 4,8 & 4,1 & 3,3 & 2,0 \\
\hline 15 & 5,8 & 5,1 & 4,4 & 3,5 & 2,1 \\
\hline 16 & 6,2 & 5,5 & 4,7 & 3,8 & 2,3 \\
\hline 17 & 6,7 & 5,9 & 5,1 & 4,0 & 2,4 \\
\hline 18 & 7,1 & 6,3 & 5,4 & 4,3 & 2,6 \\
\hline 19 & 7,5 & 6,6 & 5,7 & 4,5 & 2,7 \\
\hline 20 & 7,9 & 7,0 & 6,1 & 4,8 & 2,9 \\
\hline 21 & 8,4 & 7,4 & 6,4 & 5,0 & 3,1 \\
\hline 22 & 8,8 & 7,7 & 6,7 & 5,3 & 3,3 \\
\hline
\end{tabular}

Obtaining the maximum and economically profitable increase in fish production in pond conditions is possible using pendulum feeders that ensure the distribution of food in accordance with the regime chosen by the fish itself. The use of pendulum feeders can increase fish productivity, reduce food losses and costs, and significantly increase planting density.

The depth of installation of the feeders can vary from $10-1.5$ to $2-2.5 \mathrm{~m}$. It is important to ensure that the distance from the feeding table to the surface of the water is at least 40$50 \mathrm{sm}$ to avoid getting water on it when feeding fish and wind excitement. Immersion of pendulums to a depth, as a rule, has no strict restrictions. However, care must be taken that they do not touch the bottom of the pond, plants and other objects. The desired length of the pendulum, depending on the location of the feeder, can be considered 1.5-2 $\mathrm{m}$, and the distance to the bottom is 10$15 \mathrm{sm}$. In the case of very dense fish landing, the distance from the pendulum to the bottom of the pond does not matter.

The process of teaching fish to eat from selffeeders for each pond, depends on the specific conditions where it can proceed in different ways. Usually, active consumption of animal feed coincides with the spring rise of water temperature. Therefore, in order to accustom the fish to the places where the feeders are based, food should be distributed first directly under the pendulums. A sign of the active response of fish to the self-feeding trough is the formation of a "rash funnel" inside them.

\section{CONCLUSION}

Currently, the development of economically profitable fish farms in different regions of the country requires fish production using a scientifically based technological system, the basis of which is the effective feeding of fish. Operation of pendulum feeders will help to fully realization of the benefits of self-feeding. 


\section{REFERENCES}

1. Gorbunova A.V., Kostin V.E. "Prospects and opportunities for the introduction of digital technologies into aquaculture governance system" IOP Conference Series: Earth and Environmental Science, Volume 422, Issue 1, 10 January 2020.

2. Niyozov D., Gafforov H. Fish fiding. Bukhoro publishing, 2012

3. Fedorchenko V.I. and other fishbiological standards for the operation of pond farms. Moscow:VNIIPRH, 1985.

4. Moiseev P.A., Azizova N.A., Ichthyology, Moscow: 1981.

5. Fedorova V.D., Kapkova V.I. Practical hydrobiology of freshwater ecosystems. Moscow: 2006

6. Korbeynik A. Technology of processing and commodity science of fish and fish products 2002

7. Khusenov S.K., Niyozov D.S. Fish farming basics 2010

8. Kanidiev A. N. Feed and feeding. Lectures for students of MGTA.

9. Bal V.V., Verein E. L. Technology of fish products and technological equipment. Moscow: Agropromizdat, 1990

10. Golubeva Z.S., Orlova Z.P., Hydraulic engineering of fish culture, Moscow: Food industry, 1979

11. Privezentsev Yu.A. Intensive fish farming. Moscow: JSC Agropromizdat, 1991 